\title{
STUDY \&ANALYSIS OF AN URBAN BUS AND METRO ROUTE USING VISSIM SIMULATED DATA
}

\author{
B.Brahmaiah ${ }^{1}$ and A.Devi Prasad ${ }^{2}$
}

Abstract: Delhi has been taken as study area to measure the performance analysis of the bus and multimodal transit route. The main objective of this work is to measure the performance of direct route and multimodal route in terms travel time, travel cost, transfer time, waiting time and line haul time. For this analysis, data was collected as commuter travel survey.

In this study VISSIM (simulation modal) software were used simulate the bus and metro travel times, pedestrian transfer times and waiting times at varies transit stops for selected network, and analyse the travel times and delays at various segments in the network. From the commuter travel survey questionnaires and simulated travel time elements, some (OVTT, IVTT, cost, reliability, comfort age and gender) variables were used to define the utility of the two alternative route choices and construct the discrete choice (multinomial logit) model, and the choice probability of the alternative routes were analyzed for both equations.

\section{RESEARCH REVIEW}

Eluru et al. (2012) examined the effect of the performance of the public transportation system on commuter travel mode and transit route choice in Montreal, Canada. They observed the factors that discourage individuals from using public transit and also the reasons that effect transit route choice decisions. Information related to travel patterns, socio-demographic aspects and residential location was collected. Multinomial logit model was used for the travel mode choice analysis and a mixed multinomial logit model was used for the transit route choice analysis.

Sebastian et al. (2011) incorporated network topology in a route choice model for public transit network. The topological variables represent directness of the chosen route and user knowledge of the network. The necessary data for these variables is simple to obtain.

Bhatta et al. (2011) pronounced that level of service attributes are the important factors for defining the travel demand on multinomial logit model. They have made attempts to investigate

\footnotetext{
${ }^{1}$ Department of Civil Engineering Vignan's Institute Of Information Technology, Visakhapatnam, A.P, India.

${ }^{2}$ Department of Civil Engineering Vignan's Institute Of Information Technology, Visakhapatnam, A.P, India.
} 
the magnitude of such biases and finally observed that biased parameter estimates lead to poor policy decisions.

\section{BRIEF OVERVIEW OF STUDY AREA}

Apart the commuter travel survey to get an overlook of the study area,the study of two lines are considered from same origin to destination. One is the direct bus route (817) and other multimodal transit route from the same origin to destination (Najafgarh to Inderlok), in both routes most of the trips patterns observed are work-based trips. Some of them are leisure trips.

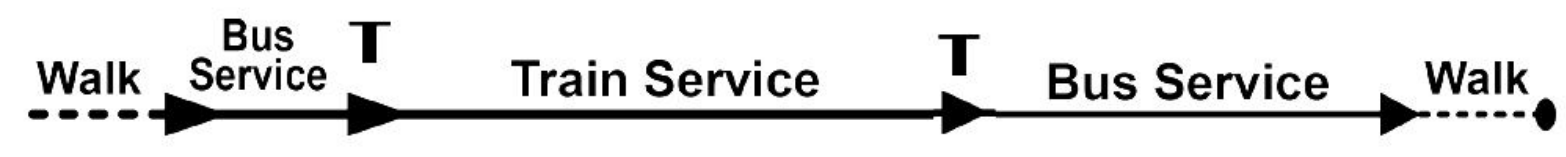

Walk Bus Service Walk

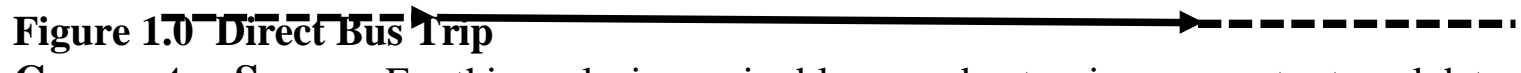

Commuter Survey:For this analysis required large and extensive commuter travel data

i). Personal Information of the passenger: Gender, Age, Income, and Purpose of Trip.

ii). Travel Information of the passenger: Origin, Destination, Access mode and Access time, Egress mode and Egress time, Transfer Time and Wait time at each switch point, In-vehicle time. iii). Passenger Satisfaction Measures in terms of speed, cost, comfort, reliability and transfer.

\section{METHODOLOGY}

\section{Performance Measures}

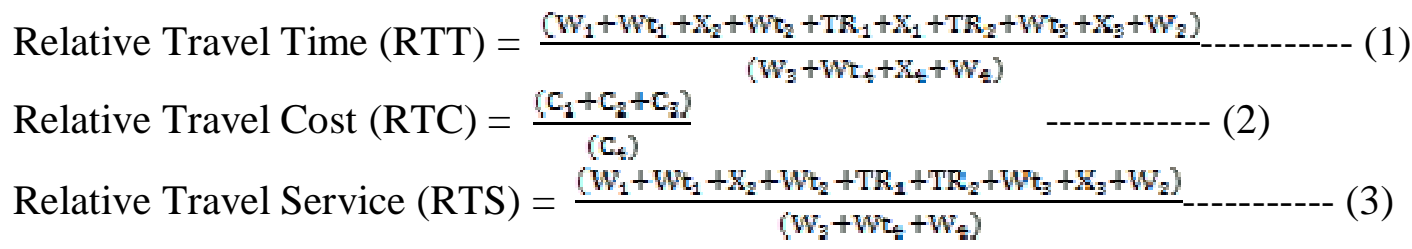

Data Collection

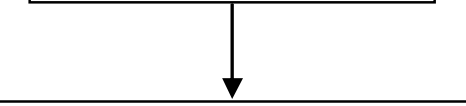

Simulation of Travel Times by Using VISSIM Software

Figure.2.0 - Flow Chart of Metho Simulated Travel Times Data Bus and Multimodal Transit Route

Where

$\mathrm{W}_{1,2,3,4}=\quad$ Walking Time fro Calibration and Validation of Model's , home to nearest

$\mathrm{Wt}_{1} \mathrm{t}_{2} \mathrm{t}_{3} \mathrm{t}_{4}=\quad \begin{aligned} & \text { bus stop, bus stop to destination } \\ & \text { Waiting Time for Ruc at Arioin Metro }\end{aligned}$

Conclusions and Recommendations 
Bus at Transfer Location, $-2\left(\mathrm{~B}_{2}\right)$, Bus at Origin (Direct Bus Route)

$\mathrm{X}_{1,2,3,4}=\quad$ Travel Time From Origin to Transfer Location $-1\left(\mathrm{~B}_{1}\right)$, Transfer Location, -1 $\left(\mathrm{M}_{1}\right)$ to Transfer Location, $-2 \quad\left(\mathrm{M}_{2}\right)$,Transfer Location, $-2\left(\mathrm{M}_{2}\right)$ to Destination,Origin to Destination

$\mathrm{C}_{1,2,3,4}=$ Travel Cost of Bus from Origin to $\mathrm{B}_{1}, \mathrm{M}_{1}$ to $\mathrm{M}_{2}, \mathrm{~B}_{2}$ to DestinationOrigin To Destination

VISSIM: It is used for simulating the travelling time of pedestrian's and vehicles. VISSIM is a Microscopic simulation model. It can analyze public and private transport operations and makes it useful for evaluation of various alternatives for transportation planning. This VISSIM software is used in this study to simulate the vehicle travel times from origin to destination, pedestrian transfer times, travel times and waiting times at various bust stops and transfer points.It can be valid for all the vehicles (i.e. buses, Bikes, HCV's, LCV's, Autos, Cars, Rickshaws and Cycles). Traffic signs (warning signs, prohibited signs, cautionary signs, speed indicators etc.,) are to be placed at necessary locations.

\section{Link Generation}

In the present work as a side unidirectional, along the considered road network no of lanes varies, (origin (Najafgarh) to Dwaraka Mor '2' lanes Dwaraka Mor to Uttam Nagar '3' lanes and Uttam Nagar to destination (inderlok) '4' lane road network)) is considered for simulation. The road geometry is plain and lane link data are shown in Figure 3.0. It is required to input the link data such as number of lanes, lane width, and link behavior type \& developed road network.

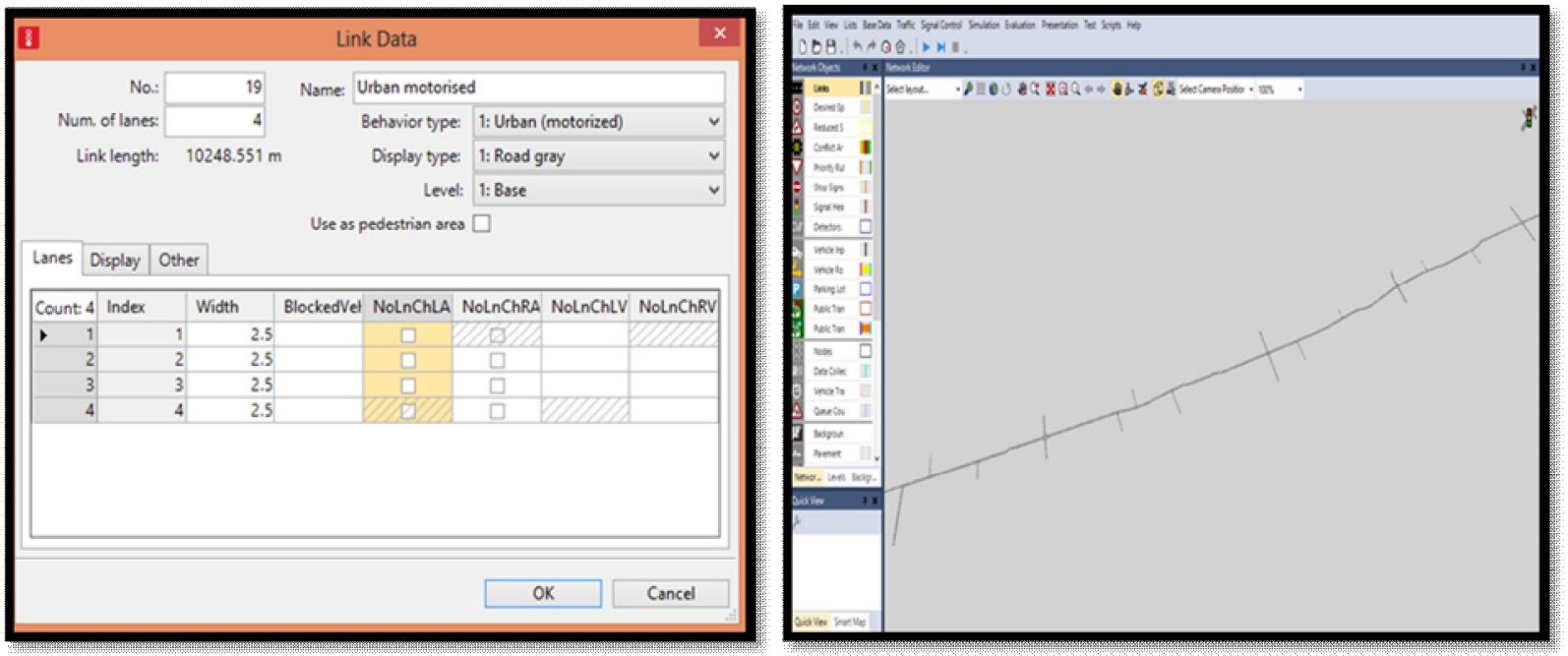

Figure 3.0Link Input Data in VISSIM, Developed Road Network

\section{Running of Simulation Model VISSIM}

After giving all input parameter to VISSIM, a travel time section of 100 meter was selected on the link at an appropriate distance away from the point of vehicle input. Desired traffic composition and input traffic volume (vehicle/hr) are assigned. For this study, simulation run time was kept 7200 second and simulation data from 900 second to 3600 second was filtered for each volume input. Fig. 4.0 show running of vehicle on a link generated in VISSIM. 


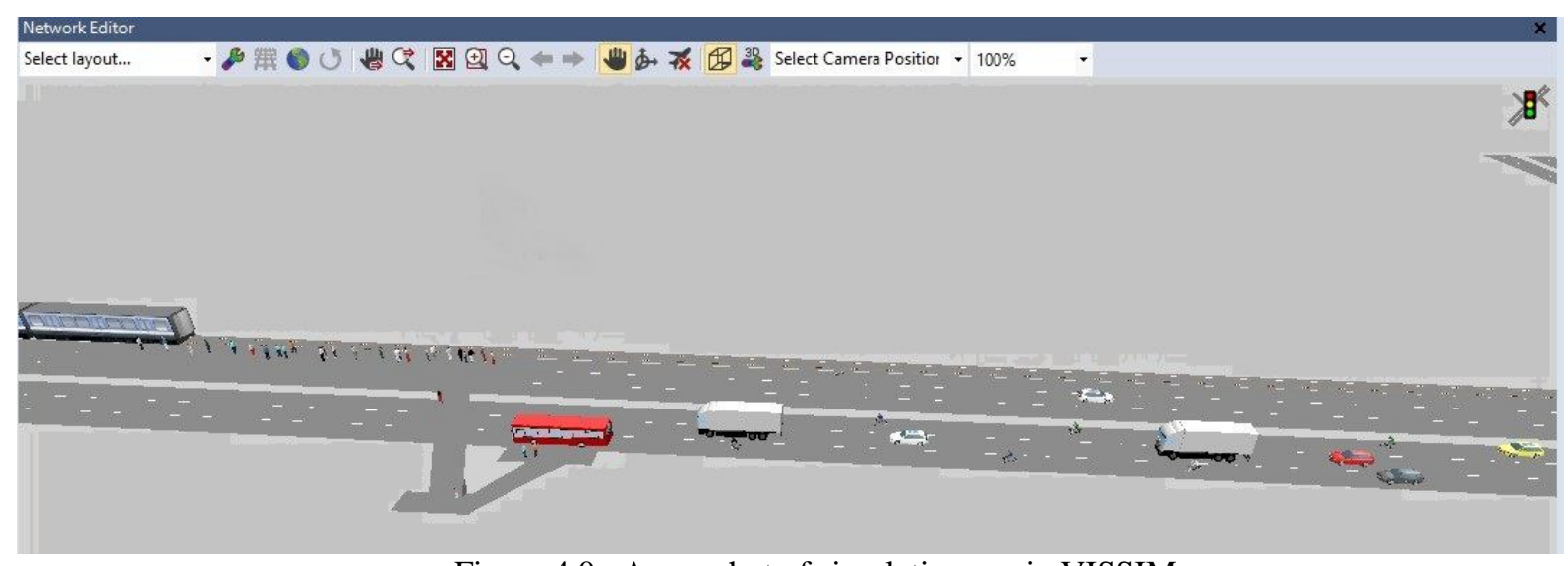

Utility Function

Figure 4.0 A snapshot of simulation run in VISSIM

$\mathrm{U}_{\mathrm{i}}=\mathrm{a}_{\mathrm{i}}+\mathrm{a}_{1} \mathrm{x}_{1}+\mathrm{a}_{2} \mathrm{x}_{2}+\mathrm{a}_{3} \mathrm{x}_{3}+\mathrm{a}_{4} \mathrm{x}_{4}$

$U_{j}=a_{j}+a_{1} x_{1}+a_{2} x_{2}+a_{3} x_{3}+a_{4} x_{4}$

Where $U_{i}$ and $U_{j}$ is the utility alternatives, $a_{i}$ and $a_{j} i s$ calibrated mode-specific constanst for the same model which represents advantages or disadvantages of mode. $a_{1}$ to $a_{4}$, coefficients are related to variables.

$\mathrm{x}_{1}=\quad$ Waiting Time for mode in minutes

$\mathrm{x}_{2}=$ Travel time (in vehicle time) in minutes

$\mathrm{x}_{3}=\quad$ Travel Cost in Rupees

$\mathrm{x}_{4}=\quad$ Access and Egress Time in minutes

\section{Multinomial Logit Model of Transit Route Choice}

The basic model estimated for predicting transit choice, the discrete choice (multinomial logit) model calculate the probability of choosing mode $i$ if disaggregate, or the proportion of travelers in aggregate case that will select a specific mode according to following relationship. General expression for the probability of choosing an alternative ' $i$ ' $(i=1,2-\cdots)$ from a set of $J$ alternatives is given as

$$
\operatorname{Pr}(t)=\frac{\exp \left(u_{i}\right)}{\Sigma_{j}^{l} \exp \left(u_{j}\right)}
$$

Where, $\operatorname{Pr}(i)$ is the probability of the decision-maker choosing alternative $i$ and $\mathrm{j}$

\section{RESEARCH OUTCOMES Commuter Satisfaction}

In the study between direct bus route and interchangeable (Bus-Metro-Bus) route, it is required to realize to what degree the overall quality of metro and bus services facilitate the commuters. Commuter travel survey questionnaire asked passengers for their view on their satisfaction in terms of Speed, Cost, Comfort, Time Reliability, and Ease of Transfer. From Fig.5.0, it can noticed that in multimodal transit route as higher percentage of passengers are satisfied in terms of speed, comfort and reliability than the direct bus route, but in direct bus route passengers are satisfied in terms of cost than the multimodal transit route. 


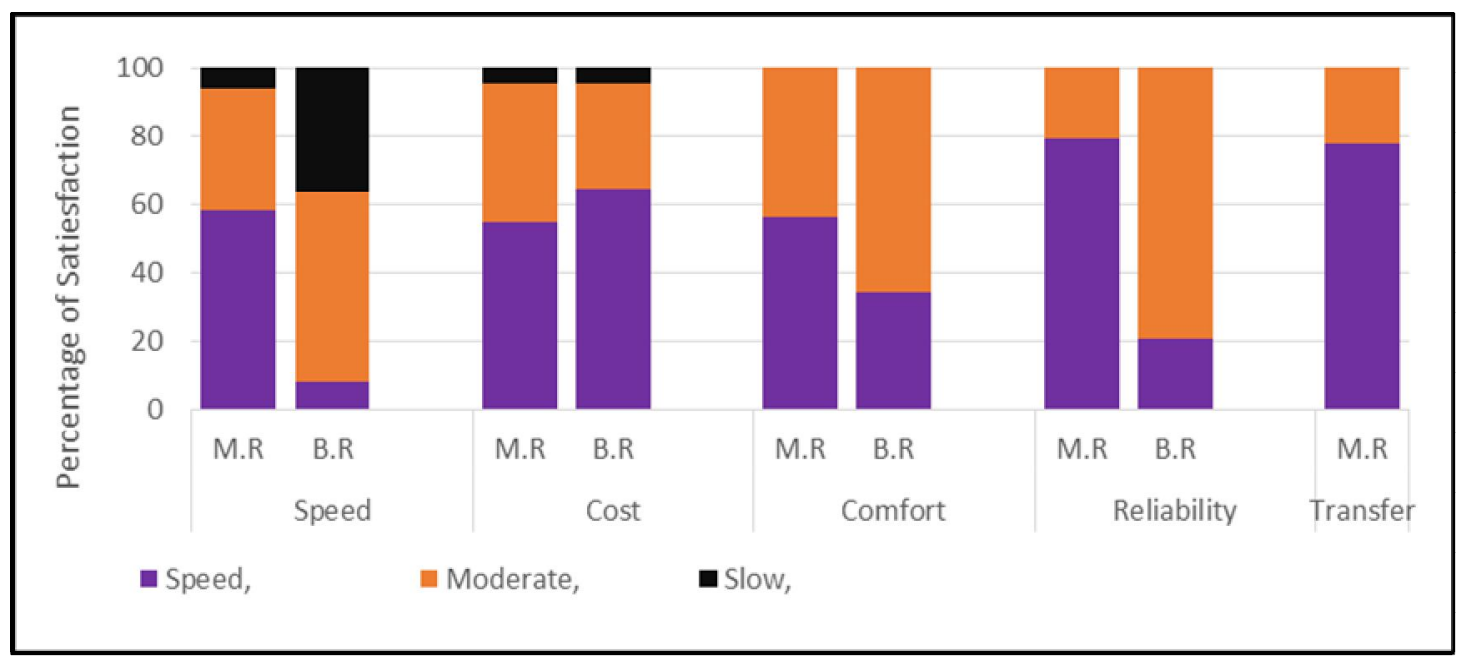

\section{Performance Measures}

Table 1.0 Performance Measures

B.R: Bus route M.R: Multimodal route

\begin{tabular}{|l|l|l|l|}
\hline Indices & Minimum Value & Maximum Value & Mean Value \\
\hline Relative Travel time & 0.622 & 0.0 .974 & 0.861 \\
\hline Relative Travel Services & 2.156 & 5.800 & 3.528 \\
\hline Relative Travel Cost & 2 & 2 & 2 \\
\hline
\end{tabular}

Simulation of Travel Times by Using VISSIM ModelSimulation results are obtained from the output database file created by VISSIM through each simulation run. Public (bus and metro) and private (Car and Two-wheeler) travel times and Pedestrian travel times are simulated, Fig.6.0shows Vehicle travel times and signal changes output database file \& it shows output window for pedestrian travel times. Simulated travel time results are summarized in table 1.0

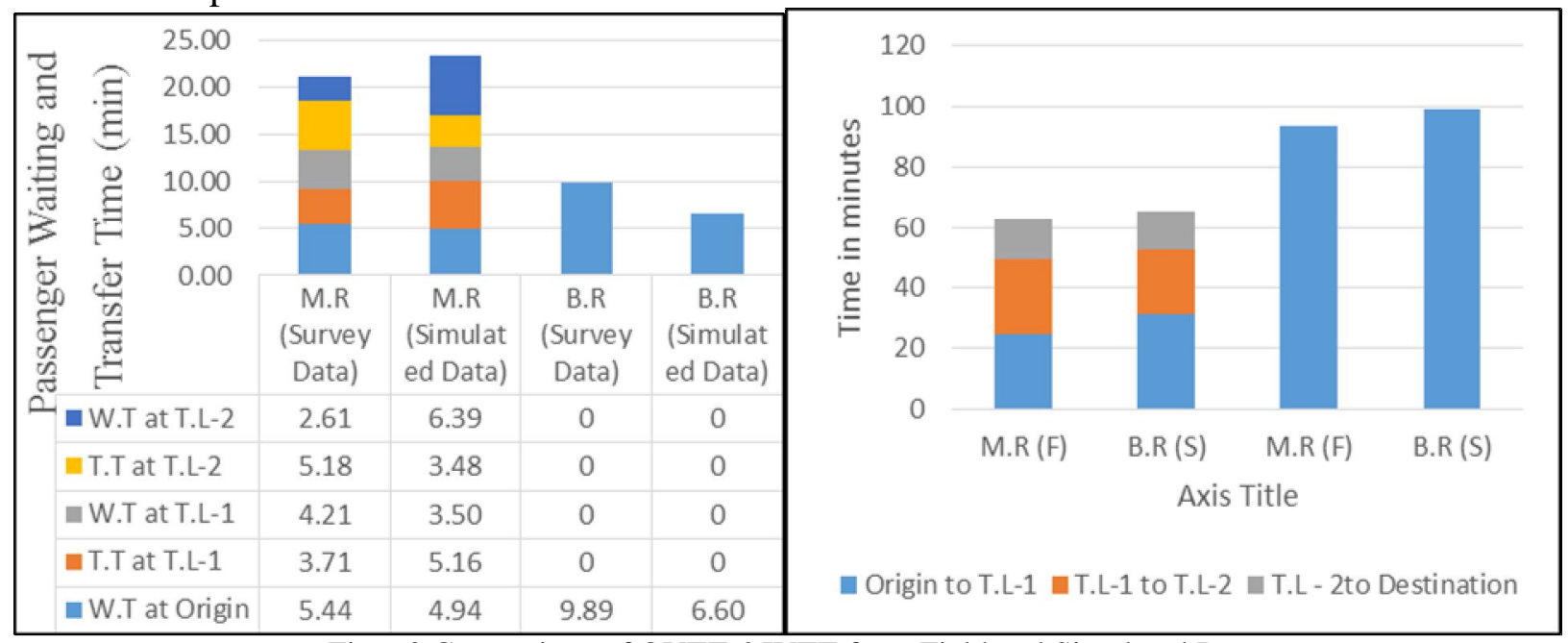

Fig 6.0 Comparison of OVTT \&IVTT from Field and Simulated Data 


\section{Multinomial Logit Model by Using Simulated Travel Time's Data}

Table 2.0 shows the Multinomial Logit model estimation parameter results from simulated data. The $\mathrm{N}$ logit software is selected to calibrate the parameter which is the premier tool for estimating discrete choice models.

U.M.R

$=-4.81694-0.05784 * 66.499-0.09969 * 20.975+0.170 * 27.875+.4816 * 0.692+$

$0.17273 * 2,475+1.00499 * 0.458+3.03453 * 0.475$

-------------- $(7)$

$\mathrm{U} \cdot \mathrm{M} \cdot \mathrm{R}=0.014875$

$\mathrm{U}_{\mathrm{B} . \mathrm{R}}=-0.05784 * 99.6-0.09969 * 7.033+0.17 * 13.067=0.08712$

Table 2.0Multinomial Logit model estimation results from simulated travel times

\begin{tabular}{|l|l|l|l|l|}
\hline Parameters & Coefficients & $\begin{array}{l}\text { Standard } \\
\text { Error }\end{array}$ & Z-Value & P-Value \\
\hline Constant & -4.81694 & 0.034 & -1.9 & 0.0502 \\
\hline OVTT & -0.05784 & 0.067 & -1.47 & 0.0961 \\
\hline IVTT & -0.09969 & 0.114 & 1.49 & 0.0933 \\
\hline Travel Cost & 0.17 & 2.559 & -1.88 & 0.0498 \\
\hline Age & -0.4816 & 0.570 & 0.87 & 0.2828 \\
\hline Gender & 0.17273 & 0.394 & -0.47 & 0.0521 \\
\hline Comfort & 1.00499 & 0.518 & 1.94 & 0.0527 \\
\hline Reliability & 3.03453 & 0.529 & 5.74 & 0 \\
\hline
\end{tabular}

\section{Probability of Alternative Route Choice}

Probability of choosing route choice are found below:

$\mathrm{P}_{\mathrm{M} . \mathrm{R}}=\frac{e^{-0.04485}}{e^{-0.094 .875}+e^{U-0.087122}}=0.146$

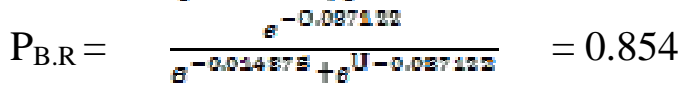

The probability of alternative multimodal transit route being chosen w.r.t direct bus route would be $=1-0.854=0.146$

\section{Calibration and Validation of Models}

This is presented in Table 3.0 It was seen that predicted percent shares of modes is near to those of observed. The validation sample was 10 percent of the total sample.

Table 3.0 Observed and Predicted Probability of Choice

\begin{tabular}{|l|l|l|l|}
\hline Generation & Choice & $\begin{array}{l}\text { Observed } \\
\text { Probability }\end{array}$ & $\begin{array}{l}\text { Probability Obtained } \\
\text { from equation }\end{array}$ \\
\hline $\begin{array}{l}\text { From simulated } \\
\text { data }\end{array}$ & Multimodal transit route & 0.50 & 0.146 \\
\cline { 2 - 4 } & Direct bus route & 0.50 & 0.854 \\
\hline
\end{tabular}

\section{CONCLUSIONS}

In this paper it is concluded that how these factors affect the performance of bus route, multimodal transit route and the choice of alternative routes.

1 .

From this study RTT says averagely $15 \%$ of travel time will be reduced by multimode transit, as per survey and simulated data.

2.

Travel cost of multimodal transit route is more because of number of mode transfers involved. Provision of singlefare system to 
multimode public transport can improve the performance of multimodal transit route and it can reduce the service time to collect ticket at every transfer.

3. The interconnectivity ratio derived for the different (access-main-egress) mode combinations will be permitted and unrealistic mode chains are eliminated.

4. The travel time coefficients indicate the negative effect depicting travel time of transit increases, its probability of choosing decreases. The model results demonstrates that

Cost, in-vehicle time and out-vehicle travel time are playing a significant role in traveler's choice behavior.

5. Attribute 'age' is having negative impact which means, as age of the individual increases, interest to travel in multimodal transit route reduces.

6. Attributes comfort and reliability are calculating utility for multimodal transit route, their increase in value increases the probability in choosing multimodal transit route.

7. As per simulated travel time metro takes very less IVTT '22' minutes (from Dwaraka mor to Moti Nagar) compared to bus travel ' 56 ' for same distance. Because bus has to face congestion and traffic signals which were almost absent in case of metro.

\section{REFERENCES}

[1]. Bharat, P.Bhatta., and Larsen, I. (2011), "Errors in variables in multinomial choice modeling: A simulation study applied to a multinomial logit model of travel mode choice", Transport Policy 18, PP. 326-335.

[2]. Sebastian, R., Juan, C., and Louis, de, G. (2011), "A topological route choice model for metro", Transportation Research Part A. 45, PP.138-147.

[3]. Eluru, N, Chakour, V., and El-Geneidy A. (2012). Travel Mode Choice and Transit Route Choice Behavior in Montreal: Insights from McGill University Members Commute Patterns. Public Transport: Planning and Operations, 4(2), PP. 129-149

[4]. Agarwal, P. K. and Singh, A.P. (2010), "Performance Improvement of Urban Bus System: Issues and Solution” International Journal of Engineering Science and Technology,Vol. 2(9), PP. 4759-4766.

[5]. Chen, L., Yang, F., Cheng, Y., Yao, Z. and Xu Zhang, (2014), "Urban Public Transport Choice Behavior Analysis and Service Improvement 1 Policy-making: A Case Study from the Metropolitan City, Chengdu, China", TRB 2014 Annual Meeting, PP.1-14.

[6]. Madhav, G.B. and Murtaza, H. (2007), "An analysis of public bus transit performance in Indian cities", Transportation Research Part A. 41, PP.961-981.

[7]. Pawan Kumar and Parida, M. (2011), "Vulnerable Road Users in Multi Modal Transport System for Delhi", PP. 38-46.

[8]. Piet H.L and Lanser, S.H. (2005), "Modelling route choice behavior in multi-modal transport networks" Transportation, Vol. 32, PP. 341-368.

[9]. Stephan, K., Martin, D. and Theo, A. (2004), "Multimodal public transport: an analysis of travel time elements and the interconnectivity ratio", Transport Policy 11, PP.265-275. 